\title{
Use of a detachable snare with polyglycolic acid sheets in a simple and novel shielding method for post-endoscopic submucosal dissection ulcers
}

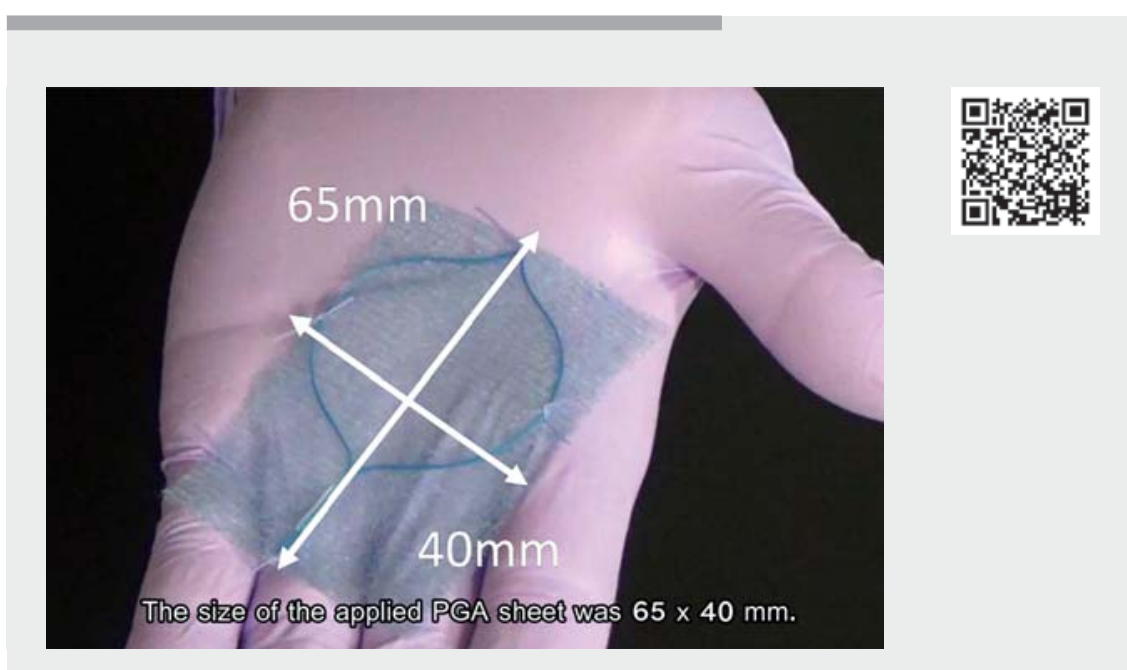

$\checkmark$ Video 1 A single polyglycolic acid (PGA) sheet of $65 \times 40 \mathrm{~mm}$ is easily and quickly applied to a post-endoscopic submucosal dissection ulcer using a detachable snare.
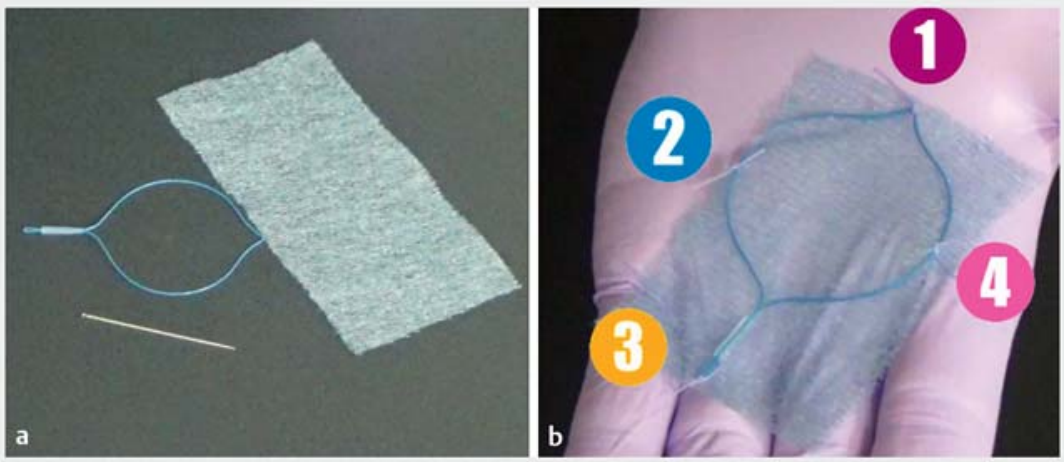

Fig. 2 Photographs showing: a the equipment used, which consisted of a polyglycolic acid (PGA) sheet and a detachable snare; $\mathbf{b}$ the PGA sheet attached to the snare at four points using silk thread.

Many reports have described a shielding method involving the use of polyglycolic acid (PGA) sheets and fibrin glue as a means to prevent post-endoscopic submucosal dissection (ESD) complications [1-5]. During this procedure, however, a PGA sheet under little tension easily shrinks when exposed to mucus. Therefore, appropriate PGA sheet delivery is required to keep the sheet dry and maintain its shape.
We demonstrate a simple and novel shielding method with autologous fibrin glue and a PGA sheet ( Video 1 ). We performed gastric ESD for a 20-mm lesion at the lesser curvature of the body. The size of post-ESD ulcer was $40 \times 30 \mathrm{~mm}$ ( Fig. 1). The equipment used consisted of a PGA sheet (NV-M-015G; Gunze, Kyoto, Japan) and a detachable snare (HX-400U-30; Olympus, Tokyo, Japan) ( Fig.2a). First, a PGA sheet was cut to

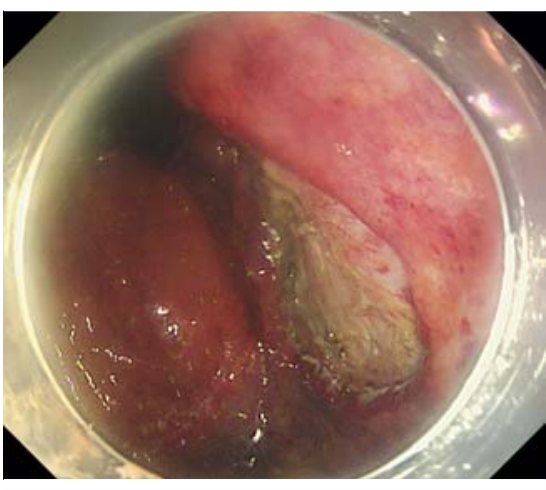

- Fig. 1 Endoscopic image showing a $40 x$ 30-mm post-endoscopic submucosal dissection ulcer on the lesser curvature of the stomach.

the size of the endoscopic detachable snare $(65 \times 40 \mathrm{~mm})$ and four points on the PGA sheet were connected to the snare using silk thread ( $\mathbf{F i g . 2} \mathbf{b}$ ). The sheet was captured by an endoscopic clip (ROCC-D-26-235-C; Micro-Tech, Nanjing, China) and anchored using clips around the sides of the gastric floor. This method resulted in the ulcer being fully covered by a single PGA sheet ( $\triangleright$ Fig.3a). The fixed PGA sheet then had autologous fibrinogen and thrombin sprayed onto it simultaneously to bond it. The procedure time was 5 minutes. Follow-up endoscopy the day after the ESD showed full coverage of the ulcer by the PGA sheet ( $\triangleright$ Fig. $\mathbf{3} \mathbf{b}$ ).

In this method, the detachable snare prevents the sheet from shrinking, even when it comes into contact with mucus. Moreover, this novel shielding method is a more rapid procedure because it allows a large size sheet $(65 \mathrm{~mm})$ to be applied in one go. In our study, we found that, using this method, a large PGA sheet can be easily applied to a post-ESD ulcer in a short time.

Endoscopy_UCTN_Code_TTT_1AO_2AD 

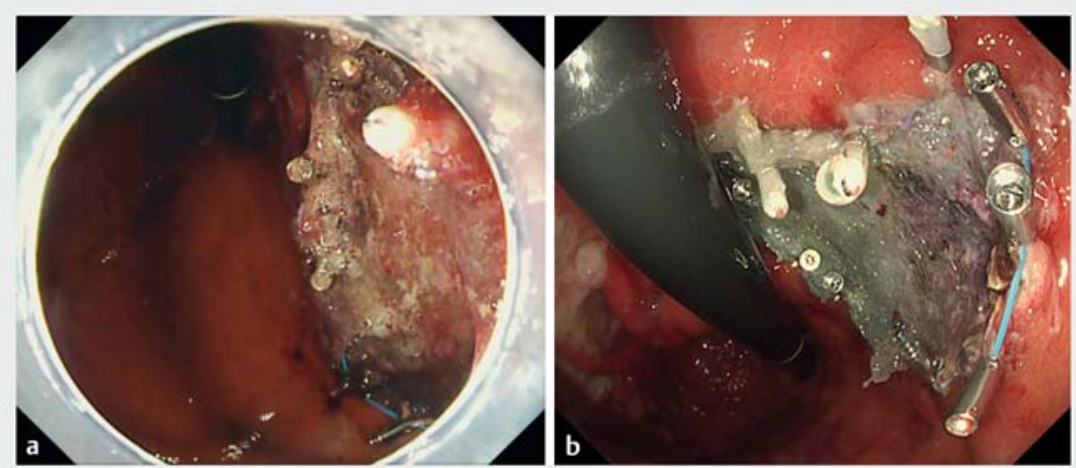

- Fig. 3 Endoscopic images showing: a the ulcer bed fully covered by a single polyglycolic acid (PGA) sheet; $\mathbf{b}$ continued full coverage of the ulcer by the PGA sheet on follow-up 1 day after the endoscopic submucosal dissection.

\section{Competing interests}

The authors declare that they have no conflict of interest.

The authors

Yoshiaki Kimoto', Ken Ohata', Eiji Sakai², Akiko Ohno ${ }^{3}$, Takafumi Ito ${ }^{4}$, Yosuke Tsuji ${ }^{5}$, Hideyuki Chiba ${ }^{6} \odot$

1 Department of Gastrointestinal Endoscopy, NTT Medical Center Tokyo, Tokyo, Japan

2 Department of Gastrointestinal Endoscopy, Yokohama Sakae Kyosai Hospital, Yokohama, Japan

3 Department of Gastroenterology and Hepatology, Kyorin University School of Medicine, Tokyo, Japan

4 Department of Gastroenterology, Keiyu Hospital, Tokyo, Japan

5 Department of Gastroenterology, Graduate School of Medicine, The University of Tokyo, Tokyo, Japan

6 Department of Gastroenterology, Omori Red Cross Hospital, Tokyo, Japan

\section{Corresponding author}

\section{Ken Ohata, MD, PhD}

Department of Gastrointestinal Endoscopy, NTT Medical Center Tokyo, 5-9-22 Higashigotanda Shinagawa-ku, Tokyo 141-8625, Japan

ken.ohata1974@gmail.com

\section{References}

[1] Tsujii Y, Kato M, Shinzaki S et al. Polyglycolic acid sheets for repair of refractory esophageal fistula. Endoscopy 2015; 47: E39-E40

[2] Nakano Y, Takao T, Kodama Y et al. Endoscopic plombage with polyglycolic acid sheets and fibrin glue for gastrointestinal fistulas. Surg Endosc 2019; 33: 1795-1801

[3] Tsujii Y, Fujishiro M, Koike K et al. Polyglycolic acid sheets and fibrin glue decrease the risk of bleeding after endoscopic submucosal dissection of gastric neoplasms (with video). Gastrointest Endosc 2015; 81: 906 912
[4] Oda I, Nonaka S, Abe S et al. Is there a need to shield ulcers after endoscopic submucosal dissection in the gastrointestinal tract? Endosc Int Open 2015; 3: E152-E153

[5] Takimoto K, Imai Y, Matsuyama K et al. Endoscopic tissue shielding method with polyglycolic acid sheets and fibrin glue to prevent delayed perforation after duodenal endoscopic submucosal dissection. Dig Endosc 2014; 26: 46-49

Bibliography

Endoscopy 2022; 54: E389-E390

DOI 10.1055/a-1550-2209

ISSN 0013-726X

published online 9.8.2021

(C) 2021. Thieme. All rights reserved.

Georg Thieme Verlag KG, Rüdigerstraße 14 , 70469 Stuttgart, Germany

\section{ENDOSCOPY E-VIDEOS}

https:/|eref.thieme.de/e-videos

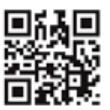

Endoscopy E-Videos is an open access online section, reporting on interesting cases and new techniques in gastroenterological endoscopy. All papers include a high quality video and all contributions are freely accessible online. Processing charges apply (currently EUR 375), discounts and wavers acc. to HINARI are available.

This section has its own submission website at

https://mc.manuscriptcentral.com/e-videos 